\title{
Who Benefits from New Transportation Infrastructure? Using Accessibility Measures to Evaluate Social Equity in Transit Provision
}

\author{
Kevin Manaugh \\ $\mathrm{PhD}$ student \\ School of Urban Planning \\ McGill University \\ Suite 400, 815 Sherbrooke St. W. \\ Montreal, Québec, H3A 2K6 \\ Canada \\ Tel.: 514-762-6545 \\ Fax: 514-398-8376 \\ E-mail: kevin.manaugh@mail.mcgill.ca
}

\author{
Ahmed M. El-Geneidy (corresponding author) \\ Assistant Professor \\ School of Urban Planning \\ McGill University \\ Suite 400, 815 Sherbrooke St. W. \\ Montreal, Québec, H3A 2K6 \\ Canada \\ Tel.: 514-398-8741 \\ Fax: 514-398-8376 \\ E-mail: ahmed.elgeneidy@mcgill.ca
}

January 2011

For referencing please use: *Manaugh, K., \& El-Geneidy, A. (2012). Who benefits from new transportation infrastructure? Using accessibility measures to evaluate social equity in public transport provision. In K. Geurs, K. Krizek \& A. Reggiani (Eds.), Accessibility and Transport Planning: Challenges for Europe and North America (pp. 211-227). Edward Elgar, London, UK. 


\section{Who benefits from new transportation infrastructure? Using accessibility measures to evaluate social equity in transit provision}

Transit provision has the potential to address several important societal goals: reducing GHG emissions, cutting traffic congestion, spurring economic development, creating jobs, as well as giving access to destinations regardless of car ownership. Understanding who benefits from new transit projects is a key factor in analyzing the sustainability of a system. This article explores the potential effects of proposed transit infrastructure projects in the 2007 Montreal transportation plan on residents of socially disadvantaged neighborhoods in Montreal, Canada. A social disadvantage index is used to identify neighborhoods in need of attention. We then model accessibility and travel time changes as a result of proposed transit infrastructure. These two measures are used to quantify the benefits at the regional and personal scales. Based on our analysis, the Montreal transportation plan is relatively equitable, though some areas benefit much more than others at the regional scale as well as at the personal scale. Balancing economic, environmental, and equity goals of transit plans is a complex and challenging process. It is recommended that policy makers carefully consider who will benefit from transit improvements when prioritizing among projects, using accessibility measures at the regional scale, and traveltime improvements at the personal scale. 


\section{INTRODUCTION}

A principal function of public transit is to provide accessibility to all members of society, particularly to those with limited mobility choices. As issues of equity and fairness gain importance in transportation planning, understanding who benefits from new and existing transit services has become an increasingly important topic. Transit providers, however, struggle to address two, often opposing goals: providing service that attracts new riders, while striving to better serve current users. Both environmental and economic goals tend to focus on attracting new riders, as replacing car trips has more emission-reducing and revenue-generating potential than improving service for current users. This dichotomy manifests itself in many North American regions as some municipalities prioritize suburban rail systems, for instance, over improved inner-city bus lines. Suburban rail has the potential to make significant reductions in green house gas emissions (GHG) if it succeeds in causing a mode change. However, the qualityof-life benefit to an inner-city resident with low job accessibility due to poor or unreliable public transit is minimal - apart from universal gains in air quality enjoyed by all.

This paper examines the extent to which proposed transit infrastructure projects in the City of Montreal, Canada transportation plan (MTP) benefit disadvantaged populations. First, we identify neighbourhoods with both high levels of social disadvantage (based on income, immigration status, and education levels) and transportation disadvantage (low levels of current

job access). Then, accessibility to employment opportunities are modeled using both existing and new transit networks. A before and after comparison of the level of access and change in travel time will allow us to identify neighborhoods that will benefit the most from the new plan. Benefits from new transit projects are quantified as an increase in access to opportunities and decline in travel time to desired destinations. Accessibility measures concentrates on quantifying the benefits at the regional scale, while the travel time measures concentrate on the personal scale. In short, this study tries to develop a methodology that can answer three research questions using readily available data and simple measures of land use and transportation interaction. 1) Are increases in accessibility to jobs due to the implementation of transportation plans reasonably distributed throughout the socio-economic gradient? 2) Do these jobs match with the 
labor market for socially disadvantaged populations? And 3) Are decreases in travel time equitably distributed in the region?

\section{LITERATURE REVIEW}

In recent decades, urban transportation planning has shifted in focus from increasing infrastructure capacity for automobile traffic to broader policies with environmental and social dimensions (Hall 1997; Lindquist 1998; Banister and Gallent 1999; Jabareen 2006; Marsden, Lucas et al. 2007; Carmona and Sieh 2008). Plans now include goals that express principles of sustainable development such as improving air quality, reducing automobile dependency, and promoting active modes of transportation including public transit. However, while performance indicators and goals have become somewhat codified for environmental and economic goals of transit systems, equity goals lack clear appropriate indicators for measuring progress. If no measures exist to monitor progress toward certain goals, planners may prioritize other goals or be led away from them in the planning or evaluation process (Meyer and Miller 2000; Briassoulis 2001; Handy 2008). Urban planners and engineers are in need of tools with which to evaluate plans and projects for goals that are less easily quantified. In addition these measures should be applicable at various scales, individual and regional.

There is a history of discussion about the meanings of "equity", "fairness", and "justice" in fields ranging from philosophy to economics. The ambiguity of the meanings of these concepts has in all likelihood led to confusion about what equity might mean to a transportation planner (Murray and Davis 2001). In the planning context, “equity planning” has been defined as a responsibility that planners have to "influence opinion, mobilize underrepresented constituencies, and advance and perhaps implement policies and programs that redistribute public and private resources to the poor and working class” (Metzger 1996 p. 113). In a transportation setting, this could refer to giving disadvantaged populations higher accessibility and more mobility choices - regardless of ability to pay, perhaps even at reduced rate. This view, often known as "vertical equity" deliberately gives benefits to one group - the poor - and not those deemed to be well-served and/or with an ability to pay full price for a given service. 
Findings from the 2001 National Household Travel Survey show clear correlations between income and transit use. Roughly 57\% of all transit trips and $78 \%$ of bus and light rail trips are made by households with income less than $\$ 40,000$, while only $13 \%$ of commuter rail trips are in this income category (Pucher and Renne 2003). However, while transit users are predominantly poor, it does not follow that transit provision always benefits poorer residents. In many regions, in fact, it is just as likely that suburban residents enjoy new, efficient, and comfortable transit, while inner-city residents ride uncomfortable, unreliable, and often overcrowded bus lines. Los Angeles and Washington DC are examples of cities where research has shown this to be the case (Bae and Mayeres 2005). Also, wealthier individuals make much longer transit trips. As many transit providers either charge a flat fee for transit use or fares that are not truly related to distance, it is possible that poor users are "subsidizing" the rich (Bae and Mayeres 2005).

The role that public transit plays in providing access to job locations for those with limited mobility options has long been argued as a key goal in transit planning (Sanchez, Shen et al. 2004; Horner and Mefford 2005; Currie 2010). Recent transportation plan goals have more explicitly addressed this, in addition to economic and environmental goals. However, the difficulty is that these goals are not always complementary. Walker (2008), claims that there are two opposed "poles" in transport goals. One is based on the idea of patronage while the other is focused on coverage. Patronage goals are an integral part of both economic and environmental focuses; more people using transit represents both more revenue and fewer people using more polluting modes. Coverage goals focus on providing service to those who need it the most regardless of whether the route is profitable. Thus, environmental and economic goals of transit could lead planners to focus on capturing new riders at the expense of current transit users. Replacing car trips has more emission-reducing and revenue-generating potential - and is more easily measured. Coverage goals, on the other hand would include such ideas as minimizing discrepancies in levels of accessibility amongst socio-economic, racial and immigrant status categories. While these two goals may not be mutually exclusive in all cases, Walker contends that they often lead to difficult decisions. A large and growing body of work explores these tradeoffs between equity and other “traditional” transport goals (Murray and Davis 2001; Kwan and Weber 2003; Horner and Mefford 2005; Currie 2010; Grengs 2010). 
Much of the work concerning levels of access to employment opportunities among socioeconomic gradients is based on spatial mismatch theory (Kain 2004). Recent work has shown that the issue may be characterized as "modal mismatch", where the locations are not necessarily separated by geographic space as much as by difficulty of getting to a desired location by transit or active means. In other words, with a car, such job locations would be easily accessible (Grengs 2010). Pickup and Giuliano (2005) describe a cycle where those without access to a vehicle are isolated from jobs and other services. This leads to further "area-based" social exclusion. In particular, many newcomers to cities first locate in areas with low job access and near existing newcomers. Apart from access to an individual's employment, transit also offers a poor substitute to the automobile in finding and interviewing for potential job opportunities (Sanchez, Shen et al. 2004).

In perhaps an extreme example of favoring equity over environmental and economic goals, Grengs (2010) argues that offering subsidies to the poor in order to purchase automobiles is potentially a viable solution. He is careful to point out that this may only be true in certain circumstances. For example when transit system is underdeveloped and providing these subsidies could be a cheaper and more efficient solution. In conclusion, there is clearly a healthy debate over the extent to which transportation goals should focus on economic factors and issues of social welfare and equity.

\section{METHODOLOGY}

In order to measure changes in accessibility levels and travel time brought about by the projects proposed in the Montreal Transportation Plan (MTP), existing and proposed transit infrastructure are modeled in a Geographic Information System (GIS). The transit projects include the new Light Rail Transit system (LRT or Tram) lines, the rail link to the airport, extensions of the commuter rail and metro systems, the new Bus Rapid Transit (BRT) lines, and increased reliability and travel speeds for existing bus lines thanks to signal-priority measures and/or reserved lanes (Figure 1). We are conceptualizing transit in this research as primarily a mode to connect workers to their place of employment, particularly for those without other 
viable options. The other important roles that transit may play in connecting people to shopping and social activities are not included in our analysis. This research will involve two phases of data preparation prior to the analysis phase. The first is identifying areas with high concentrations of social and transportation disadvantaged population. The second is generation of before and after MTP accessibility measures and travel time change matrixes.

The measure of accessibility used in quantifying the impact of the MTP is the cumulative opportunities measure. It is a simple measure to calculate and uses readily available data. In addition it is easily understood and communicated. It counts the number of opportunities that can be reached within a predefined travel distance or time (El-Geneidy and Levinson 2007), for example the number of jobs that can be reached by public transit within 30 minutes of travel time. A major advantage of this measure, beside the simplicity in explanation, is the high level of correlation with other complex measures like gravity based measures of accessibility (ElGeneidy and Levinson 2006). This measure is generated for both before and after periods for every project in the MTP. These measures of accessibility will enable the understanding of changes at the regional scale. However, we did use a more involved accessibility measure for identifying socially disadvantaged areas; this is explained below.

On average, in Canada, a one way transit trip is around 52 minutes (Turcotte 2005) . The 52 minutes comprises access time, waiting time, in-vehicle time, egress time and transfer time if a transfer was present. In our analysis we use 30 minutes of in vehicle as the standard for the measures of accessibility, which is a reasonable approximation of what users are willing to spend on in-vehicle-time.

Finally, information related to home and work location of every person residing in the Montreal metropolitan region is obtained from Statistics Canada. Travel time using public transit is calculated for each individual before and after the implementation of the MTP. This is done by linking each zonal pair back to individuals. In this way, changes in travel times associated to every project in the MTP are calculated for each individual. This will enable a better understanding of the effect of changes at the individual level and create a bridge between more data-intensive individual accessibility measures and zonal-based approaches. 
Three indicators are explored to evaluate the extent to which the proposed projects in the MTP provide equitable access.

1. The impact of each transit project in the plan on areas shown to be socially disadvantaged in terms of accessibility to jobs with trips of 30 minutes in-vehicle time or less. This analysis will focus on jobs requiring a high school education or less.

2. The change in travel time to Montreal's 6 employment centers by transit from the identified disadvantaged areas.

3. The potential time savings based on actual current job locations (from detailed home and work location data from Statistics Canada).

Mapping, tables, and statistical analysis are used to highlight the benefits and differences among neighborhoods and projects.

\section{DATA}

The unit of analysis is the Traffic Analysis Zone (TAZ) which was provided by the Québec Ministère des Transports (MTQ). The MTQ also provided the research team with travel time information for transit that was generated by a travel demand modeling software. Employment and demographic information was extracted from the 2006 Census conducted by Statistics Canada, while the transit network information was received from the Société de Transport de Montreal (STM). Access to aggregated home and work location data was provided by the MTQ Services des affaires socio-economiques.

Simulated congested A.M. peak travel times were obtained from two different government agencies for transit travel times. In order to model the proposed projects, new travel time matrices were generated. A transit travel time matrix was generated in a GIS environment using each of the transit stops closest to each TAZ centroid as both origins and destinations. Travel times on the transit network were estimated on the basis of the average operating speed of each individual transit line using the prepared GIS transit network. This method assumes that there is no delay at a transfer between lines. To correct this, a linear regression model was built to compare the simulated travel times to the travel times provided by the MTQ. 


\section{THE MONTREAL STUDY CONTEXT}

Montreal is located on an island in the St-Lawrence River. Comparatively speaking, Montreal has developed in a rather sustainable fashion, with an average metropolitan population density of about 6,000 persons per square mile of urbanized territory and with a modal share of 22\% for public transit in the morning commute to work (Communauté métropolitaine de Montréal 2010). The city has a subway system which extends into two off-island suburbs and a suburban train system which reaches far into the metropolitan periphery. Both systems are focused on the CBD, where the majority of jobs are located. The other two largest employment centers are located elsewhere on the Island of Montreal; employment is growing in off-island suburbs as well (Shearmur 2006). Figure 1 shows the Montreal metropolitan region, along with the existing and proposed transit lines and the location of the 6 major job centers. 


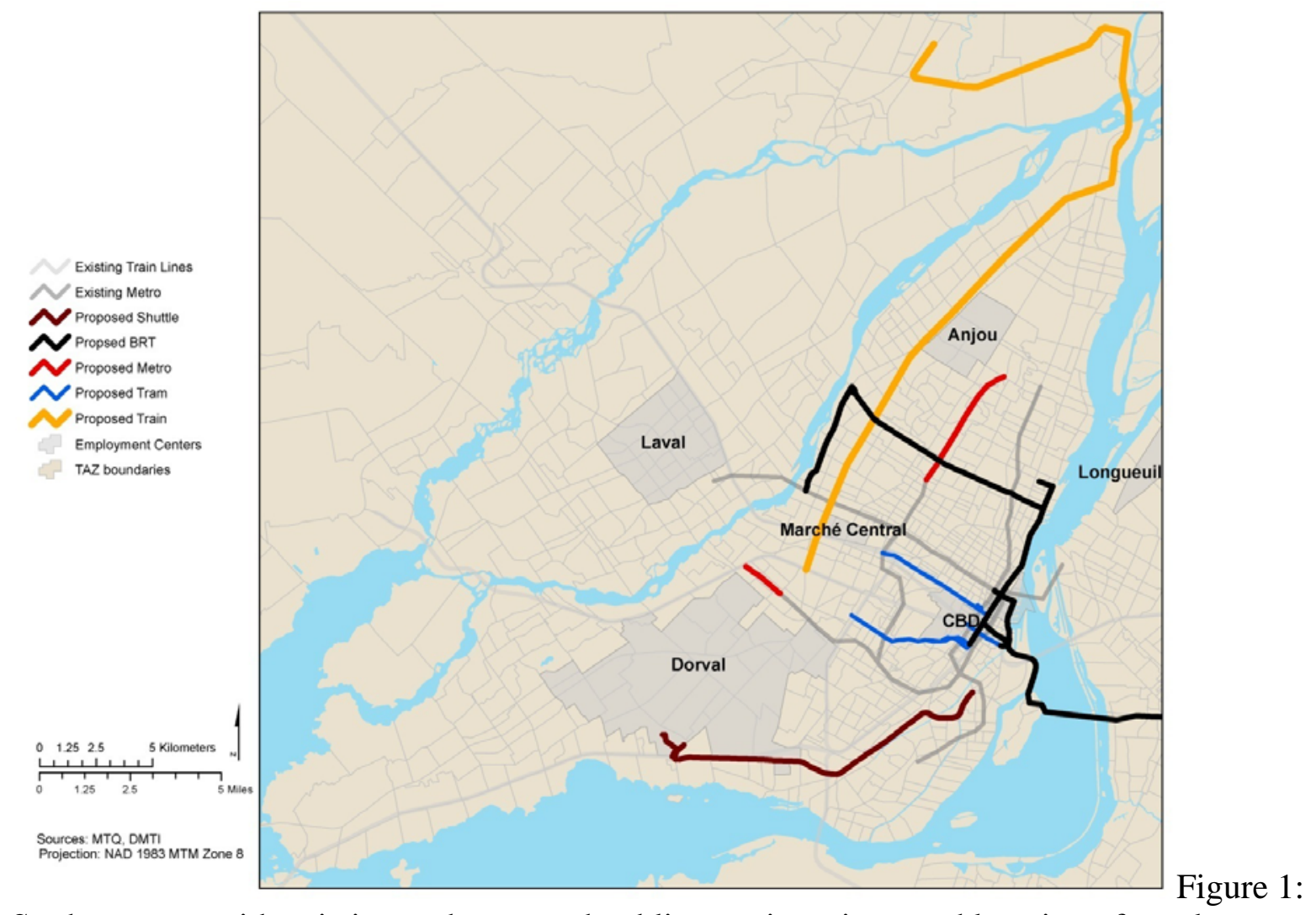

Study context with existing and proposed public transit projects and location of employment centers

The overarching goal of the MTP is to make public and active transportation the preferred modes of everyday travel in order to reduce automobile dependency and to meet other sustainability aims (Ville de Montréal 2008). The MTP contains no performance measures or indicators to assess if projects will help make transit the preferred modes of travel. The plan presents only one objective that can be easily measured: increase transit ridership by $8 \%$ by 2012, and by $26 \%$ by 2021 . The remaining performance measures included in the plan are: change in the volume of greenhouse-gas emissions, reduction in accident rates, and total transitservice hours (Ville de Montréal 2008). Equity issues are not explicitly addressed in the plan. Moreover, none of these measures can effectively help prioritize the various projects contained in the plan.

\section{ANALYSIS}

\section{Socially Disadvantaged Population}


We first identified those neighborhoods most in need by using a composite index comprised of 4 indicators plus an employment accessibility measure. The indicators are: median household income, percentage of residents that are foreign-born, percentage of adults with high school education as the highest educational attainment, and percentage of residents who use transit for work trips. In addition to these four factors, we included a measure of accessibility to low-skill jobs requiring only a High School education accounting for competition from those of a similar education levels. This measure is known as the inverse balancing factors of the doubly constrained spatial interaction model measure of accessibility (Wilson 1971). The scores from all five indicators were standardized (Z-score), a measure which determines how far (plus or minus) a given value is from the mean. These scores were then summed, giving a simple social disadvantage index. We then took the highest (worst) decile neighborhoods as the socially disadvantaged neighborhoods. This index has precedence in the literature on social disadvantage (Bauman, Silver et al. 2006).

In this manner, the identified socially disadvantaged areas are predominantly characterized by low income, transit dependent, immigrant households with low educational levels, who, in addition to these linguistic and material constraints, also have poor accessibility to employment positions that they are likely to be seeking. Figure 2 shows a map of socially disadvantaged areas. Table 1 shows mean values to highlight how these particular neighbourhoods differ from the regional average in these key indicators of social disadvantage and exclusion. 

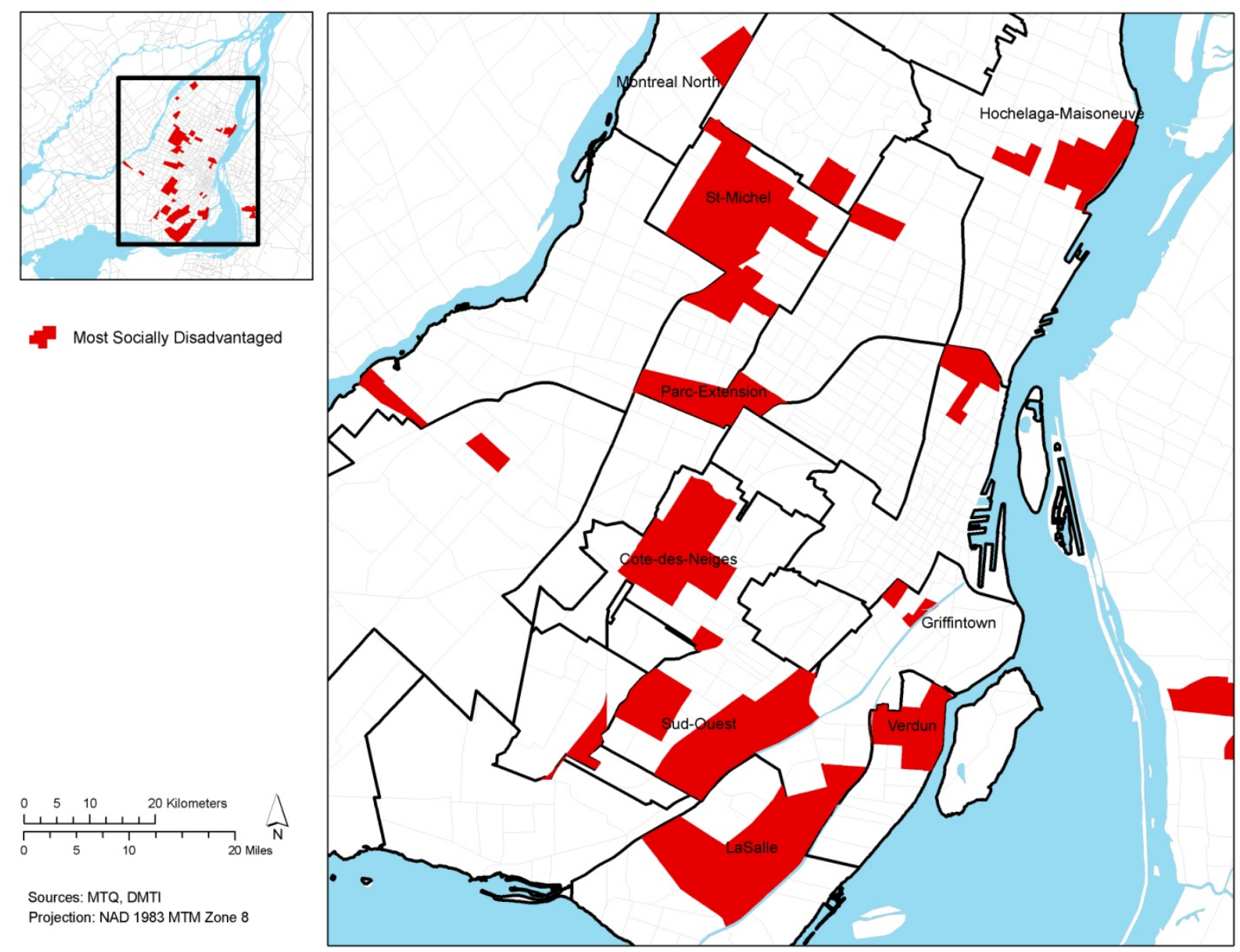

Figure 2: Identification of socially disadvantaged areas

Table 1: Comparison of socially disadvantaged neighborhoods and regional average

\begin{tabular}{lcc}
\hline Indicator & $\begin{array}{c}\text { Socially } \\
\text { Disadvantaged }\end{array}$ & Overall \\
\hline High school educational attainment as highest level & $13.0 \%$ & $10.8 \%$ \\
Visible minority & $32.0 \%$ & $16.7 \%$ \\
Median Household Income (CAD) & 32,803 & 52,392 \\
Transit Modal Split & $44.3 \%$ & $23.2 \%$ \\
\hline All variables are significantly different P<0.001, two sample t test with unequal variance \\
\hline
\end{tabular}

Some indicators such as visible minorities and income are quite different; all differ significantly $(\mathrm{p}<0.001)$ using a two sample $\mathrm{t}$ test with unequal variance. As transit equity goals include increasing human interaction, increasing access to destinations and reducing social 
isolation, these neighborhoods are arguably the most important to prioritize in giving increased choice and accessibility.

\section{Accessibility Impacts of Projects}

A first step to understand the effects of the new projects is to observe a map with the changes in accessibility to low skilled jobs. The initial examination of accessibility change maps would seem to suggest that the MTP is indeed equitable. In fact, a two sample t-test of the most and least socially disadvantaged neighborhoods shows that the most socially disadvantaged (highest quartile) areas benefit from a higher increase in accessibility to low-wage jobs than the least disadvantaged (lowest quartile). Due to the configuration of Montreal's transit system and the clustering of these low-income neighborhoods relatively close to downtown, this is not entirely surprising. Figure 3 shows the changes in cumulative accessibility to jobs, with the most socially disadvantaged areas outlined in black. This allows a better visualization of how specific transit improvements help particular areas. In particular, we see how the BRT, metro and commuter rail line have significant effects on Montreal-North. In contrast, the airport shuttle has almost no effect on socially disadvantaged neighborhoods, or, for that matter, on the region as a whole. 


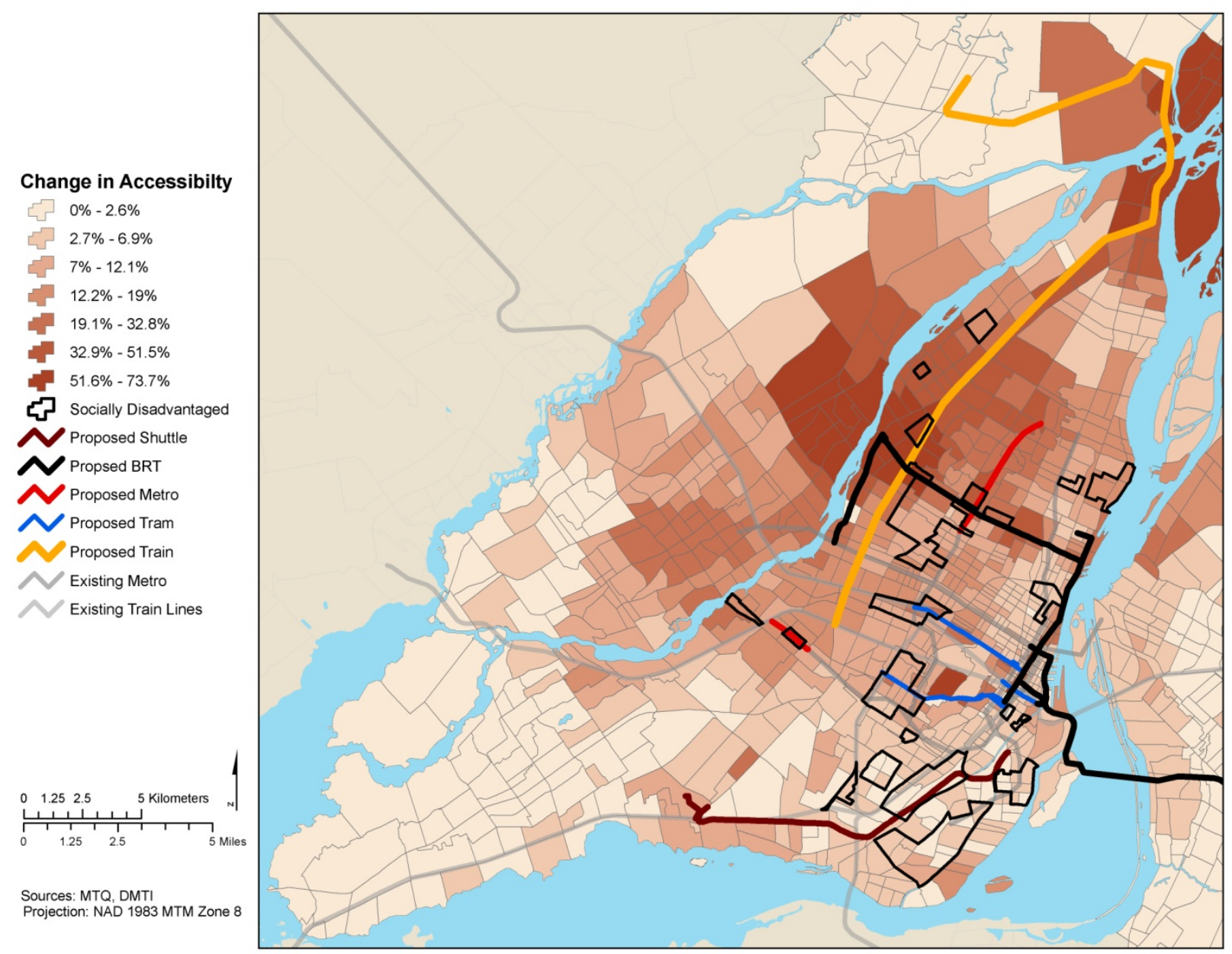

Figure 3: Changes in accessibility to low-skill jobs with all changes modeled.

Table 2 shows increase in accessibility to all jobs and to low-skilled jobs in particular. In a "best-case scenario", we would hope to see that the percentage increase to low-skilled jobs is higher or equal to the overall increase in access, implying that the transportation plan takes into account the needs of the current residents of the given neighbourhoods. In fact, this is the case in many neighborhoods, Hochelaga-Maisoneuve and Parc-Extension in particular. However, particularly in Montreal-North and St-Michel the overall increase is extremely large, yet the increase to appropriate jobs is much smaller. Focusing on all jobs could easily misrepresent which jobs are truly accessible and which are not based on skills, knowledge and experience. This focus on residents' current needs is also the principal reason why travel time to current jobs will be the focus of the next section of the study. 
Table 2: Percentage increase in accessibility to jobs (cumulative) overall and for low-skilled jobs requiring only High School education or less.

\begin{tabular}{|c|c|c|c|c|c|c|c|}
\hline & & ALL & METRO & TRAIN & TRAM & BRT & Shuttle \\
\hline \multirow[t]{2}{*}{ Cote-des-Neiges } & Low skilled jobs & $11.1 \%$ & $4.2 \%$ & $1.0 \%$ & $2.9 \%$ & $1.3 \%$ & $0.0 \%$ \\
\hline & All jobs & $10.9 \%$ & $3.8 \%$ & $0.6 \%$ & $3.0 \%$ & $1.7 \%$ & $0.0 \%$ \\
\hline \multirow{2}{*}{$\begin{array}{l}\text { Hochelaga- } \\
\text { Maisonneuve }\end{array}$} & Low skilled jobs & $13.7 \%$ & $10.5 \%$ & $0.5 \%$ & $2.1 \%$ & $5.1 \%$ & $0.0 \%$ \\
\hline & All jobs & $13.2 \%$ & $7.8 \%$ & $0.2 \%$ & $3.7 \%$ & $3.3 \%$ & $0.0 \%$ \\
\hline \multirow[t]{2}{*}{ Montreal-North } & Low skilled jobs & $49.8 \%$ & $6.4 \%$ & $45.5 \%$ & $0.9 \%$ & $24.1 \%$ & $0.0 \%$ \\
\hline & All jobs & $161.7 \%$ & $7.9 \%$ & $124.4 \%$ & $0.7 \%$ & $40.3 \%$ & $0.0 \%$ \\
\hline \multirow[t]{2}{*}{ NDG } & Low skilled jobs & $3.4 \%$ & $1.6 \%$ & $0.0 \%$ & $0.3 \%$ & $0.8 \%$ & $0.2 \%$ \\
\hline & All jobs & $3.4 \%$ & $1.5 \%$ & $0.0 \%$ & $0.6 \%$ & $1.0 \%$ & $0.1 \%$ \\
\hline \multirow[t]{2}{*}{ Parc-Extension } & Low skilled jobs & $14.7 \%$ & $7.4 \%$ & $7.2 \%$ & $3.2 \%$ & $3.1 \%$ & $0.0 \%$ \\
\hline & All jobs & $10.8 \%$ & $4.5 \%$ & $4.3 \%$ & $2.7 \%$ & $2.3 \%$ & $0.0 \%$ \\
\hline \multirow[t]{2}{*}{ Saint-Michel } & Low skilled jobs & $22.8 \%$ & $8.5 \%$ & $10.5 \%$ & $0.7 \%$ & $12.2 \%$ & $0.0 \%$ \\
\hline & All jobs & $59.0 \%$ & $7.6 \%$ & $11.2 \%$ & $1.3 \%$ & $36.1 \%$ & $0.0 \%$ \\
\hline \multirow{2}{*}{$\begin{array}{l}\text { SudSouth- } \\
\text { OuestWest }\end{array}$} & Low skilled jobs & $2.4 \%$ & $0.3 \%$ & $0.0 \%$ & $1.1 \%$ & $1.1 \%$ & $0.0 \%$ \\
\hline & All jobs & $3.4 \%$ & $0.1 \%$ & $0.1 \%$ & $1.5 \%$ & $1.7 \%$ & $0.0 \%$ \\
\hline \multirow[t]{2}{*}{ Verdun } & Low skilled jobs & $2.9 \%$ & $0.6 \%$ & $0.7 \%$ & $0.3 \%$ & $1.3 \%$ & $0.0 \%$ \\
\hline & All jobs & $3.1 \%$ & $0.4 \%$ & $0.8 \%$ & $0.8 \%$ & $1.5 \%$ & $0.0 \%$ \\
\hline \multirow[t]{2}{*}{ Regional Average } & Low skilled jobs & $8.9 \%$ & $2.4 \%$ & $4.2 \%$ & $1.0 \%$ & $2.9 \%$ & $0.2 \%$ \\
\hline & All jobs & $15.0 \%$ & $2.4 \%$ & $6.3 \%$ & $1.4 \%$ & $4.5 \%$ & $0.1 \%$ \\
\hline
\end{tabular}

In order to give a fair sense of each neighborhood's improvements in accessibility, standardized (z) scores were calculated before and after the improvements. This allows us to see how each neighborhood fares relative to the regional average and therefore does not "credit" or "penalize” a neighborhood based on its current accessibility. This can be seen in Figure 4 showing the z-score before and after the improvements. The zero line represents the regional average both before and after. Thus, for example, St-Michel scores roughly 0.5 and 0.75 above the regional average before and after the changes respectively. What is perhaps most interesting is that no neighborhood crosses the line; the areas stay either above or below average. On one hand, Montreal-North, which sees dramatic improvement is still only at roughly the mean point after all changes. On the other hand, neighborhoods such as the South-West, Verdun, or NDG, while not benefitting from certain aspects of the plan are still well above average in their accessibility to employment. Comparing Table 2 and Figure 4, we can see the contrast in 
findings based on the terms of measurement used. While Table 2 might imply that certain areas suffer from lack of increased access, Figure 4 gives a slightly more nuanced analysis. That is, from a vertical equity standpoint, it could be argued that Montreal-North “deserves” more accessibility improvements than Parc-Extension or Cote-des-Neiges.

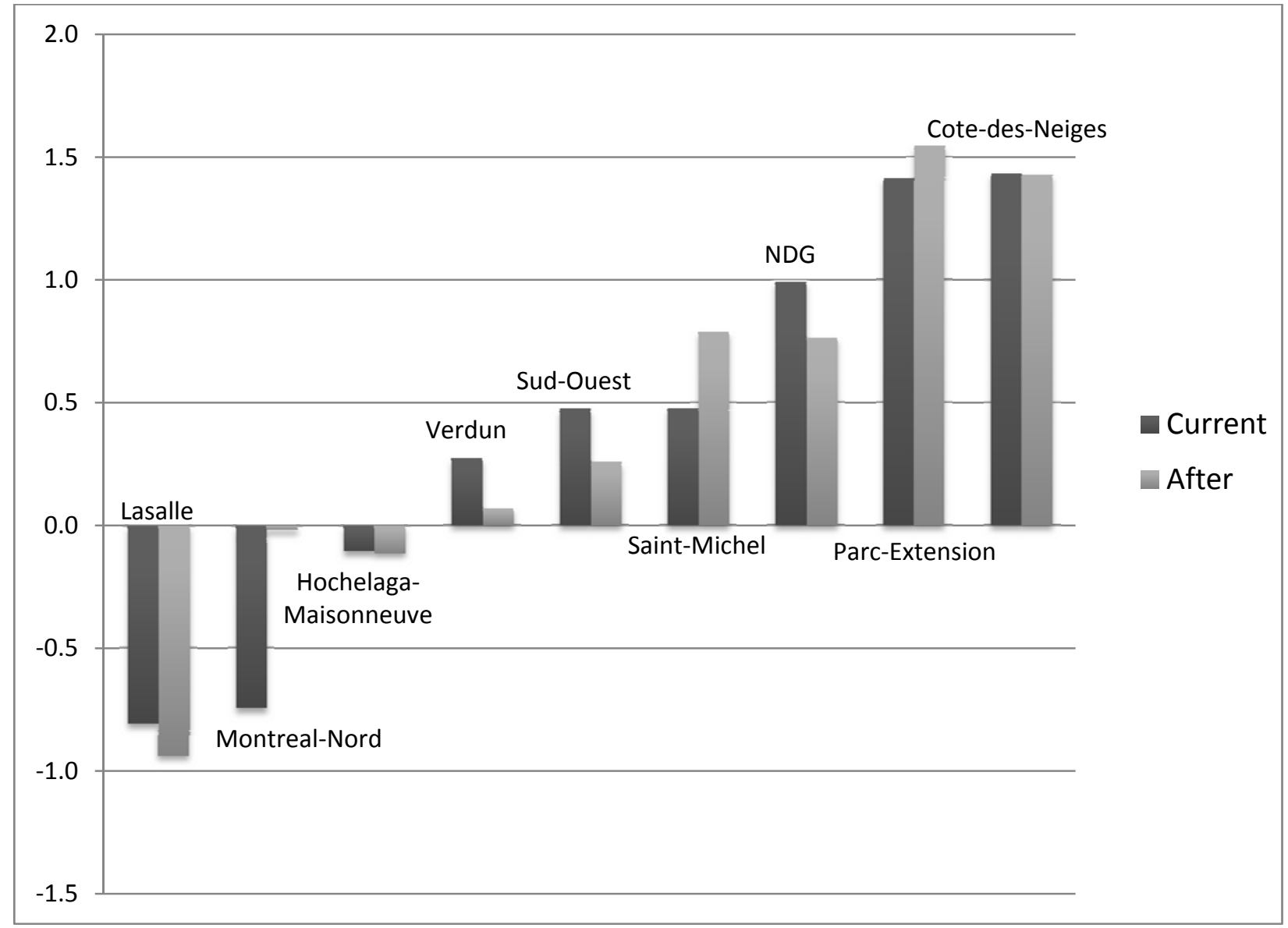

Figure 4: Z-score of low-skill employment accessibility before and after the improvements 


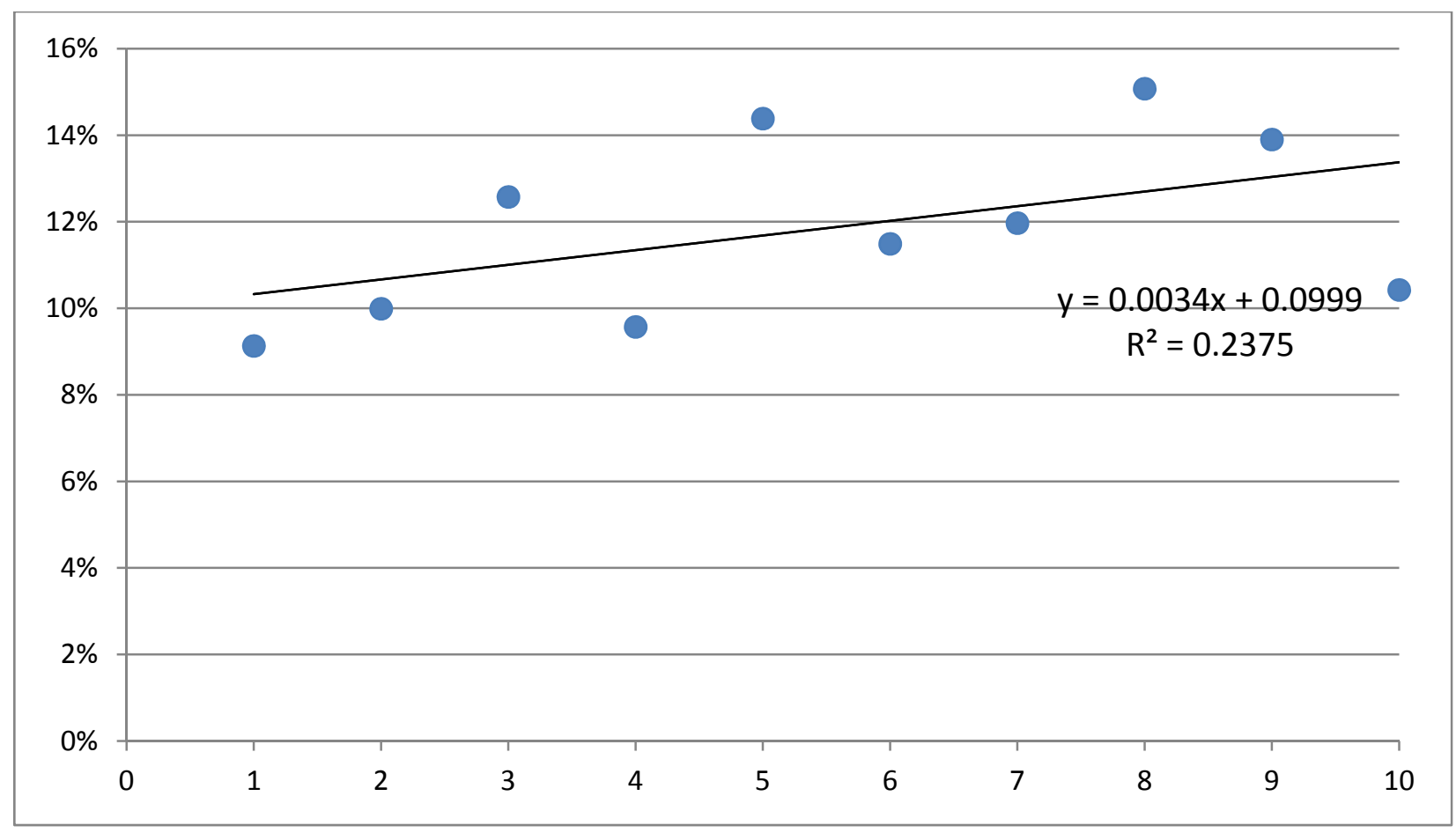

Figure 5. Average change in low-skill job accessibility (cumulative) by social disadvantage decile for all projects. Note: Metro and BRT are shown to serve socially disadvantaged populations more than more advantaged. The airport shuttle, however, serves wealthier residents more than those in need based on one-way ANOVA results shows for each individual project.

The final visualization of accessibility changes is shown in Figure 5 where we see a slight upward trend from the lowest to highest disadvantage decile in terms of improvement in accessibility to low-skill jobs. However, this relationship is only statistically significant for the Metro and BRT, which are shown to serve the disadvantaged populations more than more advantaged and the airport shuttle, which better serves the wealthier population.

\section{Travel Time Impacts of Projects}

Accessibility to jobs was seen as not necessarily the only manner to measure equitable outcomes of the plan. Accessibility provided a global picture of the effects of each project. The estimated travel time to each of Montreal's six employment centers was calculated from each of the most disadvantaged neighborhoods. This allows for two separate analyses, determining which neighborhoods are most benefitting in terms of faster access to employment centers, and by which project. It is interesting to see that Hochelaga-Maisoneuve sees little travel time 
improvement to any of the major job centers, while Parc-Extension and St-Michel see marked improvement to all job centers. Another striking finding is that access to Anjou and the CBD seem to be the most improved, all neighborhoods show at least minor improvements to these areas.

Table 3: Reduction in travel time to each of Montreal’s job centers (All changes modeled)

\begin{tabular}{lcccccc}
\hline & Anjou & CBD & Dorval & Laval & Longueuil & Marché Centrale \\
\hline Notre-Dame-de-Graces & $13.1 \%$ & $9.2 \%$ & $0.0 \%$ & $0.0 \%$ & $2.7 \%$ & $0.0 \%$ \\
Cote-des-Neiges South & $25.6 \%$ & $2.2 \%$ & $0.8 \%$ & $4.4 \%$ & $5.6 \%$ & $4.1 \%$ \\
Lasalle & $4.7 \%$ & $6.6 \%$ & $0.0 \%$ & $0.0 \%$ & $2.6 \%$ & $0.0 \%$ \\
Hochelaga-Maisonneuve & $0.6 \%$ & $5.8 \%$ & $0.7 \%$ & $9.5 \%$ & $0.0 \%$ & $12.6 \%$ \\
Montreal-North & $7.1 \%$ & $24.6 \%$ & $23.9 \%$ & $31.6 \%$ & $7.0 \%$ & $36.6 \%$ \\
Parc-Extension & $31.8 \%$ & $10.6 \%$ & $2.6 \%$ & $4.5 \%$ & $8.7 \%$ & $2.9 \%$ \\
Saint-Michel & $23.3 \%$ & $12.6 \%$ & $7.9 \%$ & $11.4 \%$ & $11.6 \%$ & $18.8 \%$ \\
South-West & $2.9 \%$ & $14.0 \%$ & $0.0 \%$ & $0.0 \%$ & $3.6 \%$ & $0.0 \%$ \\
Verdun & $2.8 \%$ & $13.5 \%$ & $0.0 \%$ & $0.0 \%$ & $4.0 \%$ & $0.0 \%$ \\
Villeray & $30.2 \%$ & $9.0 \%$ & $0.0 \%$ & $0.0 \%$ & $10.3 \%$ & $0.0 \%$ \\
\hline Overall in Region & $\mathbf{1 1 . 9 \%}$ & $\mathbf{3 . 2 \%}$ & $\mathbf{5 . 5 \%}$ & $\mathbf{3 . 8} \%$ & $\mathbf{1 . 3} \%$ & $\mathbf{0 . 2} \%$ \\
\hline
\end{tabular}

The final stage of the analysis concerns travel-time reductions based on actual home and work locations. For this, we mapped the current home-work commute for all workers in the region. We were able to estimate travel time savings for individuals as well as analyze and the number of people from a given neighborhood who will benefit from such improvements. The results are summarized in Table 4. If an area is gaining in accessibility to either unsuitable job opportunities or showing decreases in travel time to undesired locations, we could claim that the plan is not taking this neighborhood's needs into account. While we do not want to suggest reverting to focusing on mobility at the expense of accessibility, in the case of examining the equitable outcomes of the plan, it seems that this travel-time savings is a key factor.

We see that certain neighbourhoods are better served. The South-west borough, parts of NDG and Griffintown are shown to have the least benefits in terms of travel-time reduction to current jobs. On the other hand, particularly due to the BRT, train and Metro lines, Montreal North, St-Michel and Cote-des-Neiges show very high levels of benefit. This time-savings was examined as average time per person. Montreal-North again stands out as an area with high 
benefit to current residents. The last column shows estimated travel time savings in person-hours for a one-way commute. Comparing Table 1 and 4, we see that Griffintown, for example, does not benefit much in terms of increased accessibility to jobs, however, a large percentage of residents are seeing real, albeit minor, travel time savings on their commute.

Table 4: Improvements in travel time

\begin{tabular}{lccccc}
\hline & $\begin{array}{c}\text { Total } \\
\text { Workers }\end{array}$ & $\begin{array}{c}\text { \% who would } \\
\text { see a } \\
\text { reduction in } \\
\text { their current } \\
\text { commute }\end{array}$ & $\begin{array}{c}\text { \% who would } \\
\text { see a } \\
\text { reduction of } 5 \\
\text { minutes or } \\
\text { more }\end{array}$ & $\begin{array}{c}\text { Avg. time } \\
\text { saved } \\
\text { (minutes/ } \\
\text { person) }\end{array}$ & $\begin{array}{c}\text { Total } \\
\text { Hours } \\
\text { saved }\end{array}$ \\
\hline Cote-des-Neiges & 18120 & $51.1 \%$ & $7.1 \%$ & 1.3 & 37.6 \\
Griffintown & 1265 & $29.6 \%$ & $0.0 \%$ & 0.2 & 0.8 \\
Lasalle & 9795 & $13.2 \%$ & $1.1 \%$ & 0.3 & 4.1 \\
Hochelaga-Maisonneuve & 4090 & $33.7 \%$ & $3.3 \%$ & 0.8 & 7.9 \\
Montreal-North & 2135 & $66.3 \%$ & $52.0 \%$ & 6.7 & 25.8 \\
NDG & 14575 & $9.0 \%$ & $1.6 \%$ & 0.2 & 8.7 \\
Parc-Extension & 9685 & $41.7 \%$ & $15.0 \%$ & 1.6 & 25.9 \\
Saint-Laurent & 1420 & $96.8 \%$ & $8.8 \%$ & 2.7 & 6.6 \\
Saint-Michel & 9195 & $50.4 \%$ & $28.2 \%$ & 2.9 & 51.2 \\
South-West & 3415 & $20.9 \%$ & $1.6 \%$ & 0.4 & 1.7 \\
Verdun & 7610 & $22.5 \%$ & $1.9 \%$ & 0.5 & 6.0 \\
Villeray & 5145 & $30.7 \%$ & $10.6 \%$ & 1.4 & 15.4 \\
\hline Overall Region & 1031150 & $34.5 \%$ & $11.2 \%$ & 0.7 & 2776.8 \\
\hline
\end{tabular}

Based on the assumption that residents will keep their current jobs, Figure 5 shows that those near the train, metro and BRT benefit the most in terms of travel time to their current jobs. Surprisingly, the airport shuttle seems to do little to improve commuting time. The map seems to show a east/west divide with those in the western part of the island seeing much less direct benefits from the plan. However, some may argue that this actually shows the equitable aspect of the plan. The vast majority of the "low-change" areas to the west of the island are wealthy suburban-style developments, while most of the areas more affected are likely to be poor, with more recent immigrants and higher rates of unemployment. 


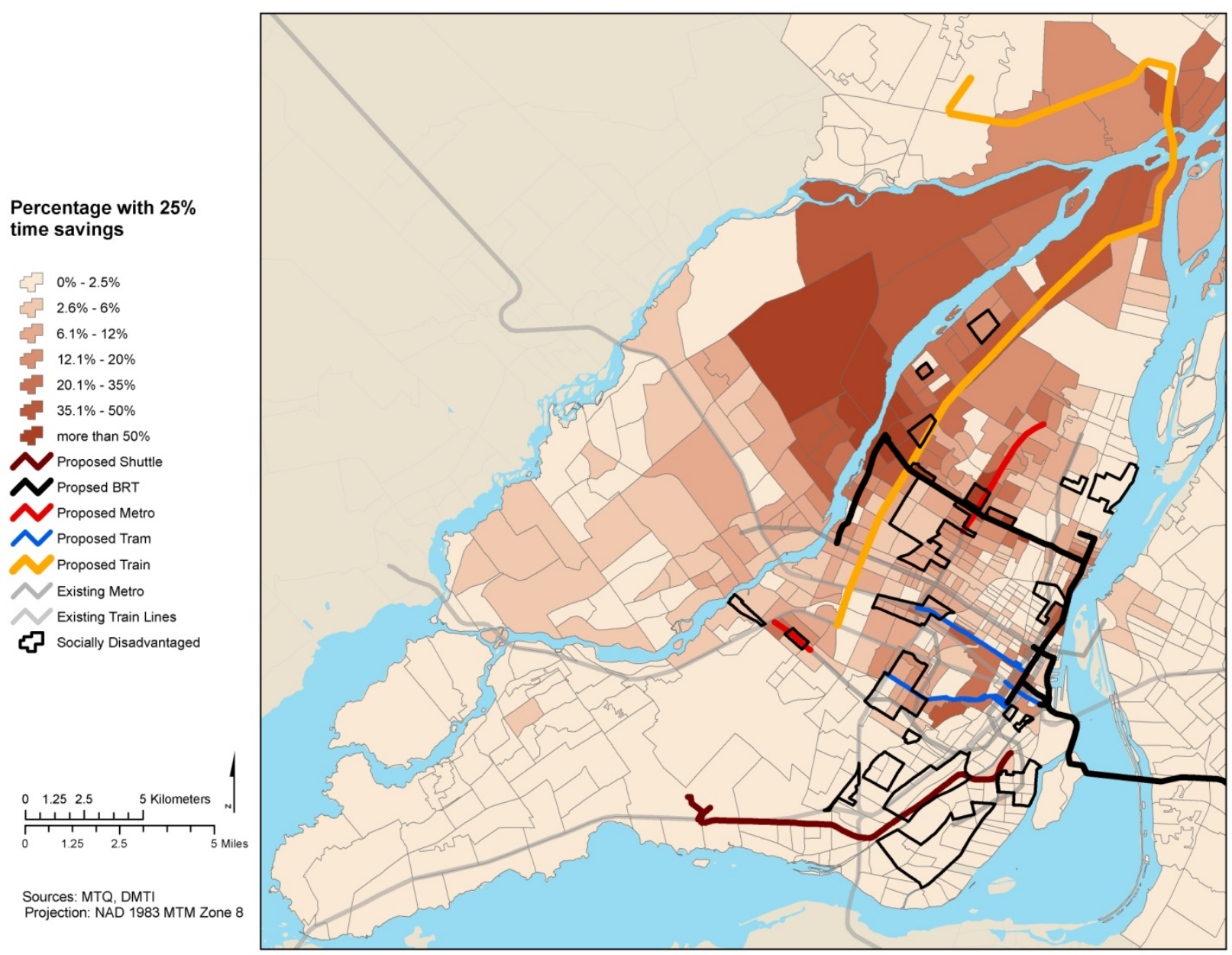

Figure 5: Percentage of residents who would see a 25\% travel time reduction or more on their current commute

\section{CONCLUSION}

This paper explores several issues related to accessibility and equity and adds to the burgeoning debate on this topic. Among other findings, it would suggest the importance of scale, definition and appropriateness of measurement. From a regional standpoint, the plan seems to succeed. Many people who presently lack good accessibility and connections to employment centers will see increased benefits. Due to the geographic location of many disadvantaged neighborhoods, and the focus of most new transit infrastructure near the CBD, the plan does provide quite well to many poorer neighborhoods. However, on a micro-scale we see that certain neighbourhoods fare much better than others. 
The measures of accessibility generated here allow for a long term vision. Having access to more jobs within the labor market increases the number of opportunities available to the disadvantaged population in the long term. On the other hand, the travel time analysis shows the short term impact on individual mobility, since each person is only concerned with how to access her existing job and to what extent the new plan will help her in doing so. Meanwhile the analysis of travel time to job centers concentrates on the long term aspect and flexibility that the plan can offer to the socially disadvantaged population in terms of job search in the future.

This paper set out to answer a relatively straightforward question; how well do currently socially isolated and disadvantaged neighbourhoods benefit from transit improvements and how is this quantified as time-savings to job locations. As sustainability goals continue to grow in importance for transit providers, it is important that easier-to-measure goals such as ridership and environmental impact do not become prioritized at the expense of considerations of equity. It is not our intention, however to take the discussion completely away from these important considerations. For example, the proposed commuter train has the potential to be both an economic force in a relatively undeveloped region as well as being a possible solution to limiting GHG emissions for both current and future residents. In fact, this could be the most beneficial project from an environmental standpoint, if the potential time savings translate into mode shift. Interestingly, we also observe what might be termed a "spillover effect" of the commuter rail. While the rail line has been primarily designed to serve residents at the periphery, the planned route and station placement may very well aid many in low-income neighborhoods. A focus on suburban mode shift is not necessarily misguided, and only becomes a concern if it leads to neglect of transit-dependent riders elsewhere. It does seem clear that the BRT lines have the possibility to both connect workers to potential jobs as well as get them to current jobs for possibly a fraction of the cost of rail improvements. However, it is beyond the scope of this paper to do a full cost/benefit analysis which weighs equity issues in some manner.

Regional transit agencies interested in providing service in an equitable manner would be encouraged to understand important characteristics of underserved populations by asking three questions. Firstly, where are the under-served populations located? Secondly, where are their places of employment? Lastly, how can they be better served? Answering these questions might 
allow for more appropriate transit solutions for the needs of these populations. Faster connections, more reliable service, new areas of access, or entirely new routes might be considered. Relatively straight-forward GIS techniques can aid greatly in answering these questions at both the regional and personal scales.

This research is not without limitations. Further research might utilize census micro-data for a more accurate exploration of who lives in certain neighbourhoods. The aggregate approach misses socially disadvantaged individuals living in other neighborhoods. Accessibility to transit was not examined thoroughly; neighbourhood-scale walkability factors play an important role in the attractiveness and comfort of using transit. Also, a fairly narrow view of the role of transit connecting workers to jobs - is utilized; however, the approach is backed up theoretically and by previous research. Modeling transit presents its own unique challenges. Different individuals might have dramatically differing attitudes and preferences towards waiting times, frequencies of stops, number of transfers, as well as type of transit mode. So, for some, one minute on a train may not equal one minute on a bus. This, however, is a subtlety that we were not able to bring into the analysis.

This paper leaves many questions unanswered. How decision-makers will adapt to changing goals of transit remains to be seen. Our results highlight the importance of multicriteria evaluation as the findings would suggest that potential environmental benefits of some projects are not necessarily aligned with issues of equity or need. It is hoped that policy-makers bear in mind these subtleties when prioritizing among projects. The simple approach outlined here shows how accessibility measures can be utilized to indicate the extent to which transit projects are equitably distributed among those with the most need. The changes in travel time highlight the personal benefits that individuals will gain from the implementation of the new projects.

\section{ACKNOWLEDGMENTS}

This work was partially funded by Le Fonds québécois de la recherche sur la nature et les technologies (FQRNT), Le Fonds quebecois de la recherche sur la societe et culture (FQRSC), and the Natural Science and Engineering Research Council of Canada (NSERC). The authors would like to thank Mr. Pierre Tremblay from the Québec Ministry of Transportation for 
providing the travel time used in the analysis. We would like thank Assumpa Cerda of the AMT for her help in generating the accessibility measures and travel time matrixes. Last but not least, we would like to thank Prof. Raphael Fischler for his feedback at various stages of this paper. All opinions in this paper are the responsibility of the authors.

\section{REFERENCES}

Bae, C. and I. Mayeres (2005). Transportation and equity. Social Dimensions of Sustainable Transport: Transatlatlantic Perspectives. K. Donarghy, S. Poppelreuter and G. Rudinger. Burlington, VT: 164-194.

Banister, C. and N. Gallent (1999). "Sustainable commuting: a contradiction in terms?" Regional Studies 33(3): 274-280.

Bauman, L., E. Silver, et al. (2006). "Cumulative social disadvantage and child health." Pediatrics 117(2): 1321-1328.

Briassoulis, H. (2001). "Sustainable development and its indicators: Through a (planner's) glass darkly." Journal of Environmental Planning and Management 44(3): 409-427.

Carmona, M. and L. Sieh (2008). "Performance measurement in planning towards a holistic view." Environment \& Planning C 26(428-454).

Communauté métropolitaine de Montréal (2010). The CMM at a glance. Montréal, Communauté métropolitaine de Montréal.

Currie, G. (2010). "Quantifying spatial gaps in public transport supply based on social needs." Journal of Transport Geography 18(1): 31-41.

El-Geneidy, A. and D. Levinson (2006). Access to destinations: Development of accessibility measures. Minnesota, Minnesota Department of Transportation: 124.

El-Geneidy, A. and D. Levinson (2007). "Mapping accessibility over time." Journal of Maps v: 76-87.

Grengs, J. (2010). "Job accessibility and the modal mismatch in Detroit." Journal of Transport Geography 18(1): 42-54.

Hall, P. (1997). "The future of the metropolis and its form." Regional Studies 31(3): 211-220.

Handy, S. (2008). "Regional transportation planning in the US: An examination of changes in technical aspects of the planning process in response to changing goals." Transport Policy 15: 113-126.

Horner, M. and J. Mefford (2005). Examining the spatial and social variation in employment accessibility: A case study of bus transit in Austin, Texas. Access to Destinations. D. Levinson and K. Krizek. San Diego, Elsivier: 193-214.

Jabareen, Y. (2006). "Sustainable urban forms: Their typologies, models, and concepts." Journal of Planning Education and Research 26(1): 38-52.

Kain, J. (2004). "A pioneer's perspective on the spatial mismatch literature." Urban Studies 41(1): 7-32.

Kwan, M.-P. and W. Weber (2003). "Individual accessibility revisited: Implications for geographical analysis in the twenty-first century." Geographical Analysis 35(4): 341-353. 
Lindquist, E. (1998). "Moving toward sustainability: Transforming a comprehensive land use and transportation plan." Transportation Research Record(1617): 1-9.

Marsden, G., K. Lucas, et al. (2007). "Assessment of capabilities for examining long-term social sustainability of transport and land use strategies." Transportation Research Record(2013): 30-37.

Metzger, J. (1996). "The theory and practice of equity planning: An annotated bibliography." Journal of Planning Literature 11: 112-126.

Meyer, M. and M. Miller (2000). Urban transportation planning, McGraw-Hill.

Murray, A. and R. Davis (2001). "Equity in regional service provision." Journal of Regional Science 41(4): 577-600.

Pickup, L. and G. Giuliano (2005). Transport and social exclusion in Europe and the USA. Social Dimensions of Sustainable Transport: Transatlatlantic Perspectives. K. Donarghy, S. Poppelreuter and G. Rudinger. Burlington, VT, Ashgate: 38-49.

Pucher, J. and J. Renne (2003). "Socioeconomics of travel behavior: Evidence from the 2001 NHTS." Transportation Quarterly 57(3): 49-77.

Sanchez, T., Q. Shen, et al. (2004). "Transit mobility, jobs access and low-income labour participation in US Metropolitan areas." Urban Studies 41(7): 1313-1331.

Shearmur, R. G. (2006). "Travel from home: An economic geography of commuting distances in Montréal." Urban Geography 27(4): 330-359.

Turcotte, M. (2005). The time it takes to get to work and back, Statistics Canada. General Social Survey on Time Use: Cycle 19.

Ville de Montréal (2008). Plan de Transport. Montréal.

Walker, J. (2008). "Purpose-driven public transport: Creating a clear conversation about public transport goals." Journal of Transport Geography 16: 436-442.

Wilson, A. G. (1971). "A family of spatial interaction models, and associated developments." Environment \& Planning A 3(1): 1-32. 